\title{
Bloody Good! The Impact of eLearning on Medical and Nursing Practice
}

\author{
https://doi.org/10.3991/ijac.v10i2.7349 \\ David Peterson $\left.{ }^{\square}\right)$, Tracey Clark, Richard Sprod, \\ Trudi Verrall, Louise English, Amanda Thomson \\ Women's and Children's Hospital, North Adelaide SA, Australia \\ david.peterson@sa.gov.au
}

\begin{abstract}
Blood transfusion is a commonly-performed medical procedure that improves and saves the lives of patients. However, this procedure also has significant risks, is sometimes used inappropriately and has substantial costs associated with the collection, testing, processing and distribution of blood and blood products.

BloodSafe eLearning Australia (BEA) (www.bloodsafelearning.org.au) is an education program for Australian doctors, nurses and midwives, designed to improve the safety and quality of clinical transfusion practice. Courses are interactive and include case studies, videos, and best-practice tips. Successful completion of a multiple-choice assessment provides learners with a certificate of completion. To date there are more than 400,000 registered learners, from more than 1500 organisations, who have completed more than 765,000 courses.

Stakeholder feedback shows that the program: provides credible, consistent education across Australia; is cost effective; reduces duplication; is 'bestpractice' elearning that is readily accessible; allows institutions to focus on practical aspects of transfusion education; results in change to clinical practice; and supports the broader implementation of a blood management strategy in Australia.

User evaluation shows that the courses have a positive impact, with $89 \%$ of respondents stating they had gained additional knowledge of transfusion practice, processes and/or policy and more than $87 \%$ reporting they will make, or have made, changes to their work practices which will improve patient safety and outcomes.

The BloodSafe eLearning Australia program provides education to a large number of health professionals across Australia. Evaluation demonstrates that these courses provide users with a consistent and reliable knowledge base that translates into changes to practice and improved patient outcomes.
\end{abstract}

Keywords—transfusion medicine, blood transfusion, elearning, evaluation 


\section{Introduction}

\subsection{Historical context}

It has been known for millennia that blood is the 'stuff of life'. The Old Testament states 'the life is in the blood' [1]. Ovid's Metamorphoses, published in 8 AD tells the story of Medea who took her '...knife and cut the old man's throat, letting all his blood out of him. She filled his ancient veins with a rich elixir... and his wasted form [was] renewed, [he] appeared in all the vigor of bright youth'[2]. Pliny described spectators drinking the blood of Roman gladiators in order to cure epilepsy [2].

The first recorded transfusion probably occurred around 1492. According to the legend Pope Innocent VIII was terminally ill. A mystic arrived in Rome and promised to cure him by exchanging his blood with that of young boys. Three 10-year old boys were selected and paid one Ducat each and then the blood of the Pope was put into the boys, and the boys' blood into the Pope. Each of the boys died shortly after, and not surprisingly, the Pope did as well [3].

It was William Harvey's discovery and documentation of the circulatory system in the early 1600 s that provided the basis for the transfusion of blood into the veins of either animals or humans. In 1667, only months apart, Jean-Baptiste Dennis in France and Richard Lower in England undertook the first successful transfusions in humans using animal blood. However, 'Denis' fifth patient had ... a transfusion reaction and the resultant uproar led to legal bans and a general public outcry that effectively stopped most transfusion experiments for decades' [4].

In 1825, after several failed attempts, the English obstetrician James Blundell demonstrated the life-saving effects of a blood transfusion to a woman with severe bleeding following childbirth [4].

While these transfusions sometimes saved lives, in many cases they also took lives as patients had reactions to the transfused blood. It was not until the discovery of blood groups, initially by Karl Landsteiner in 1901, together with advances in sterility control, preservation of blood, plastics technology, and the explosion in understanding of immunology, biochemistry, genetics and physiology, that transfusion would become a routine part of medical treatment.

\subsection{Transfusion today}

Blood transfusion is today one of the most commonly performed medical procedures, and worldwide more than 100 million units of blood are transfused each year [5]. Transfusion is used to save the lives of patients who have been injured, and it allows complex surgical procedures and medical treatments to be undertaken in order to treat and manage illness and disease.

In most countries the provision of this blood relies on altruistic, volunteer donors who freely give their blood on a regular basis. In most parts of the world blood donation is highly regulated and considerable expense is incurred, most often by govern- 
ments, to ensure that the donated blood is tested for transfusion-transmitted diseases. This results in a supply of blood and blood products that is very safe and secure.

Despite this, the transfusion of blood remains the cause of often preventable morbidity and mortality. Data from the UK-based Serious Hazards of Transfusion (SHOT) report, a blood transfusion adverse events reporting scheme, shows that in 2015 in the UK there were:

- 3288 reports made of possible adverse events related to transfusion;

- 1125 errors identified;

- 166 patients who suffered serious harm;

- 26 patients who died as a result of the transfusion; and

- At least 8 of these deaths were preventable [6].

In Australia more than 600,000 units of red blood cells were transfused to patients in 2015-16, together with a range of other specific, manufactured or processed blood components. The direct cost to supply these products to the Australian healthcare system was approximately AUD $\$ 1.2$ billion [7]. Indirect costs have been estimated at up to 4.8 times the direct costs [8].

While there is no single, mandatory reporting scheme for adverse transfusion events in Australia the available, but incomplete, data suggests that the rate and frequency of adverse events is similar to the UK [9]. Preventable errors, usually due to human error, have been well documented.

These preventable errors are commonly associated with blood being given to the incorrect patient as a result of human error. If the blood groups of the patient and the donated blood are incompatible then the transfused red cells can be destroyed by the patient's immune system, resulting in renal (kidney) failure and a range of other adverse outcomes. This can result in death of the patient. A case study example is provided below.

It is also known that transfusion is significantly overused. Somewhat paradoxically, retrospective analysis demonstrates that patients who are transfused often have worse outcomes, longer length-of-stay in hospital, and a higher rate of post-operative infection resulting in considerable additional costs to the health system [10].

\section{Improving Knowledge and Practice}

To improve transfusion practice and patient outcomes substantial effort has been applied in Australia (and other developed countries) to implement patient blood management programs and to develop guidelines and standards [11-13]. These guidelines and standards are used to inform clinical practice and have been adopted as the foundation of mandatory accreditation of hospitals.

To support these initiatives a comprehensive elearning program, BloodSafe eLearning Australia, has been developed. This program delivers consistent, up-to-date education for healthcare professionals in Australia that provides knowledge which can be applied in the clinical setting to improve patient outcomes. 
Example 1. Case Study

\begin{abstract}
A patient went to theatre for a hip replacement. Approximately one hour into the operation the anesthetist requested a nurse to 'get a unit of blood for the patient in theatre one'. The nurse did not take any documentation to identify the patient, and not knowing the patient's name, consulted the theatre list.

However on that particular day, a new patient had been added to the theatre schedule. The nurse made an assumption about the order of the patients in theatre, and retrieved blood crossmatched for a different patient. The nurse then returned to the theatre to find the anesthetist was on the phone and left the blood on an anesthetic trolley.

When the phone call was completed the anesthetist picked up the unit of blood, and without following the correct checking procedures, transfused the unit. Approximately 45 minutes later a second unit was requested. At this point it was recognized that an error had been made and the patient had been transfused with incompatible blood. Despite immediate supportive treatment, the patient died.

Source: Coroners Court NSW Australia. Confidential findings in relation to the death of Mrs S by the Coroner PJ Staunton. 5 October 2001. Not released publicly.
\end{abstract}

\title{
2.1 The BloodSafe eLearning Australia Program
}

BloodSafe eLearning Australia ${ }^{1}$ is an education program for Australian doctors, nurses, midwives, and other healthcare professionals who are part of the transfusion chain. It is designed to improve the safety, quality and efficacy of clinical transfusion practice.

The program commenced in 2007 and currently has more than 400,000 registered learners from more than 1500 hospitals and healthcare organisation. These learners have completed more than 765,000 courses

The program consists of 15 online courses that cover:

- Transfusion practice and safety including the risks and benefits of transfusion, collecting pre-transfusion blood samples, appropriate transportation of blood, administration of blood and blood products and management of transfusion reactions;

- Short, dedicated courses for staff who only transport blood (couriers, porters) or collect blood specimens (venipuncture nurses); and

- Patient blood management in specific clinical settings in order to conserve the patient's own blood and ensure the appropriate use of blood when required.

A full list of available courses is provided in Table 1.

In addition there are a range of supporting resources that include standalone videos, a mobile device app and promotional resources.

All courses are aligned with national priorities in the blood sector and are based on guidelines and standards published by the National Blood Authority [11], and the Australian and New Zealand Society of Blood Transfusion [12]. Courses are endorsed by a range of medical specialty colleges and societies.

\footnotetext{
${ }^{1}$ Free access available at www.bloodsafelearning.org.au
} 
Table 1. List of available courses

$\begin{array}{lll}\text { - Clinical transfusion practice } & \text { - Medical patients } \\ \text { - Collecting blood specimens } & \text { - Cancer } \\ \text { - Introduction to patient blood management } & \text { - Chronic kidney disease } \\ \text { - Critical bleeding } & \text { - Chronic transfusion } \\ \text { - Perioperative } & \text { - Obstetrics (for release July 2017) } \\ \text { - Critical care } & \text { - Pediatrics and neonatal (for release mid 2018) } \\ \text { - Postpartum hemorrhage } & \text { - Iron deficiency anemia mobile app } \\ \text { - Iron-deficiency anemia } & \end{array}$

\subsection{Program aims}

The program aims to improve clinical transfusion practice and increase awareness of patient blood management principles through education. It provides a nationally consistent message in accordance with relevant guidelines and assists hospitals to meet the National Safety and Quality Health Service Standard 7 - Blood and Blood Products accreditation [13].

The program undertakes to fulfill these aims by providing knowledge that can be applied to clinical practice. Major areas include:

- Error prevention - reducing harm to patients, including death, as a result of patient identification errors;

- Patient consent - ensuring that patients and/or their carers are fully informed of the risks and benefits of transfusion and have provided consent where they are able to do so;

- Implementing patient blood management by reducing the unnecessary transfusion through conservation and management of the patient's own blood - for example by treating the cause of anemia, rather than transfusion being the default option;

- Supporting national, evidence-based, blood transfusion guidelines; and

- Assisting hospitals to meet their blood transfusion education and accreditation requirements.

\subsection{Learning context}

BloodSafe elearning courses are undertaken in a situated learning context within a community of practice.

The typical learner (nurse, midwife, doctor) is in the real-world (hospital ward) and exposed to an authentic context (patients requiring transfusion). They are learning about transfusion practice, or building on existing knowledge, in order to increase their expertise as they go about their daily tasks.

All learning is asynchronous, learner-directed and is not facilitated. In some cases the elearning courses are backed up with practical skills training in the workplace. These practical classroom sessions are not facilitated or managed by BloodSafe eLearning Australia. 


\subsection{Educational design}

Courses are designed to complement the broader 'culture of learning' within healthcare settings and to provide an authentic experience for the learner. Design principles include:

- Providing real-life contexts that reflect the application of knowledge to the workplace (case studies, problem-based learning, clinical tips, resources and tools);

- Authentic activities (relevant problem-based learning, case studies, interactive learning objects);

- Access to expert performances and the modeling of processes (video of experts and peers providing clinical advice and information, modeling of best-practice clinical skills and procedures, dramatization of real-life case scenarios, access to guidelines, standards and published evidence);

- Multiple roles and perspectives (nursing, midwifery, medical and laboratory experts and perspectives);

- Collaborative construction of knowledge (reflective activities with the ability to see what others have said, links to additional information);

- Learner reflection to enable abstractions to be formed (reflective activities which focus on application to workplace). [14]

There is no 'forced' navigation or requirement to sit through narrated screens. This allows learners to move freely around the resources and select information that is relevant to their work situation and/or current knowledge base.

Courses can be accessed on a range of devices including desktop and notebook computers, and mobile devices. They are accessible from anywhere there is internet available.

A certificate is provided upon successful completion of a multiple-choice assessment. This can be used to provide evidence of completion for organisations that mandate the courses, and to meet continuing professional development requirements for professional registration with the Australian Health Practitioners Regulatory Authority and professional colleges and societies.

\subsection{Funding}

Funding for this program is provided by the National Blood Authority on behalf of all Australian governments. Funding is approved by the Jurisdictional Blood Committee, typically in 1 to 3 year cycles.

All courses are available to the learner at no cost.

\subsection{Governance}

BloodSafe eLearning Australia works within a multi-tiered governance framework consisting of key stakeholder organizations from the Australian blood sector. These stakeholders provide direction and corporate accountability. 
Course content is developed using transfusion medicine experts with elearning experience who are employed by the program. Expert and peer review is undertaken as part of the course development process using subject matter experts from the professions that make up the target audience. Most commonly this includes relevant experts from the medical, nursing, midwifery and transfusion scientist professions.

\subsection{Uptake}

The BloodSafe eLearning Australia program provides education for doctors, nurses, midwives, health professional students and other health workers who are involved in the prescription and/or administration of a blood transfusion to patients in hospitals.

As of 31 December 2016 there were:

- 1501 hospitals and healthcare organizations who use the courses for professional development and/or mandatory training of staff;

- 404,674 registered learners - made up of nurses/midwives (84.6\%), doctors (9.6\%) and other health care professionals (5.8\%);

- 766,436 courses that have been completed by these users; and

- 14,449 courses completed each month on average during the last financial year.

A comparison of uptake with registration statistics published by the Australian Health Practitioners Registration Authority [15] show that that one or more courses offered by the program have been completed by approximately $80 \%$ of nurses and midwives in Australia, who undertake transfusion as part of their clinical practice, and approximately $40 \%$ of doctors who have transfusion within their scope of practice. ${ }^{2}$

\section{Evaluation}

In order to evaluate whether the BEA program is meeting its objectives a comprehensive evaluation program has commenced.

\subsection{Data Sources}

Evaluation of the program has been undertaken using workshops, interviews and meetings with key stakeholders in order to information future directions and for quality assurance and improvement.

Individual learners are given the opportunity to provide feedback and evaluation of each course using an online survey following completion of assessment. This is used to identify improvements that can be made to the course, and to provide information on whether, and how, the course content can be applied to their work practices. This course evaluation is voluntary, and is completed by approximately $1 \%$ of learners.

\footnotetext{
${ }^{2}$ This estimation excludes registration numbers for nurses, midwives and doctors who work in clinical settings where transfusion will not be undertaken such as mental health, dermatology and others.
} 


\subsection{Program Evaluation}

Quantitative and qualitative evaluation of the program was undertaken by an external consultancy using workshops, meetings and interviews with questions tailored to the relevant stakeholder group. Table 2 outlines the key questions discussed with each stakeholder group.

Table 2. Key questions for stakeholder groups

\begin{tabular}{|c|c|}
\hline 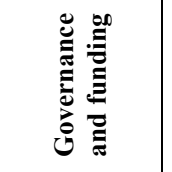 & $\begin{array}{l}\text { - What current/emerging issues are BloodSafe eLearning Australia well positioned to } \\
\text { respond to? } \\
\text { - Are the current funding arrangements appropriate? } \\
\text { - What changes would optimize BloodSafe eLearning Australia's capacity to meet its } \\
\text { strategic challenges and opportunities? }\end{array}$ \\
\hline 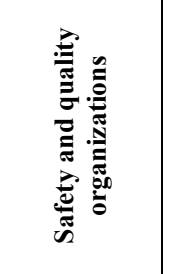 & $\begin{array}{l}\text { - How can BloodSafe eLearning Australia maximize its impact within the Australian } \\
\text { health system? } \\
\text { - Do you see opportunities for partnering with BloodSafe eLearning Australia to increase } \\
\text { course uptake or impact? What form could this take? } \\
\text { - What impact would a change to the BloodSafe eLearning Australia funding model (eg } \\
\text { - What are the opportunities for support or endorsement to assist organizations in } \\
\text { meeting safety and quality standards? }\end{array}$ \\
\hline 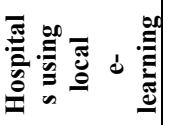 & $\begin{array}{l}\text { - How do you currently use elearning } \\
\text { - What were the key factors in your decision to maintain a local elearning presence? } \\
\text { - Do you see opportunities to engage with BloodSafe eLearning Australia in the future? }\end{array}$ \\
\hline 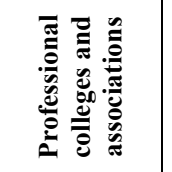 & $\begin{array}{l}\text { - Do you think BloodSafe eLearning Australia courses are well used and highly regarded } \\
\text { within your association? } \\
\text { - Do you recommend or endorse BloodSafe eLearning Australia courses Why/why not? } \\
\text { - How can BloodSafe eLearning Australia maximize its positive impact for your } \\
\text { members? }\end{array}$ \\
\hline
\end{tabular}

This review shows that key stakeholders believe the program:

- Provides credible, consistent education across Australia;

- Is cost effective;

- Reduces duplication;

- Is 'best-practice' elearning that is readily accessible;

- Allows institutions to focus on the more practical aspects of transfusion education and training;

- Results in change to clinical practice; and

- Supports the broader implementation of a blood management strategy in Australia.

Key strengths identified by stakeholders are that the program:

- Has strong governance, with a well-established framework, evidence of national collaboration, transparent reporting and sound decision making and processes in line with the funding contract requirements and expectations; 
- Provides value for money based on the quality of the product, its fitness for purpose and its impact on practice through its not-for-profit/cost-recovery model, and provision of free online learning for the sector;

- Has considerable expertise in both transfusion medicine and elearning within the team;

- Has a wide range of clinical experts who work as a collaborative community and contribute to course content, design and review; and

- Is directly aligned with the strategic direction of the blood sector in Australia and can readily respond to changing needs [16].

\subsection{User evaluation}

All users are provided with the opportunity to provide feedback by way of an online, end-of-course, completion survey. Completion is voluntary and anonymous and is not linked to their learner registration information. The survey questions cover three areas: user demographics, course design and effectiveness, and application of course content. Further information is provided in Table 3.

Analysis of 3885 end-of-course completion surveys submitted by learners shows that the program and courses provide users with a consistent and reliable knowledge base that translates into changes to practice and improved patient outcomes. Specifically:

- $89.3 \%$ of respondents report that the course(s) have provided them with additional knowledge of transfusion practice;

- $61.7 \%$ have gained knowledge that they will use to change their clinical practice;

- $83.6 \%$ are better able to identify near misses and adverse events; and

- $87.6 \%$ believe that the knowledge gained and changes they make will improve patient outcomes and safety.

Actions and changes identified by users that will improve patient outcomes and safety include: reviewing local transfusion policies and procedures to ensure they are aligned with current guidelines; reviewing blood ordering practices in stable, nonbleeding patients; assessing and treating anaemia prior to elective surgery in order to maximise the patient's own blood volume; developing and implementing massive transfusion protocols in order to ensure the best possible outcome for patients with critical bleeding; improving assessment and management of postpartum haemorrhage (massive bleeding following childbirth); and, implementing additional professional development and mentoring programs for staff in transfusion practice. Selected examples of user feedback are provided in Table 4. 
Table 3. User Evaluation Survey

\begin{tabular}{|l|ll|}
\hline & Profession (list items) \\
\hline & - State/territory of work (list items)
\end{tabular}

Table 4. Examples of user feedback

[At first] I groaned when I saw it was a two hour course. But the written and visual teaching strategies made learning interesting and the course was finished without me looking at the clock. Midwife 16 August 2015.

As a student I have observed blood transfusions many times in clinical practice, however until now was largely unaware of the importance of the involved observation and documentation. Reactions to.. blood products can be fatal, careful monitoring of transfused patients will in future be a priority for my care.

Student Nurse 20 June 2016

[BloodSafe eLearning courses are] really good and interactive, the case studies made me feel the impact of not practicing safely.

Student Nurse 29 February 2016

[Following this course I will now] review our massive transfusion protocol and make sure that I am able to easily access a copy, even though I rarely am required to use it. Also I will use tranexamic acid in my practice. Medical Consultant/Specialist 18 June 2016

I am very impressed. An easy to use, engaging and highly relevant learning tool. I had to do this as a mandatory requirement in working as a Registered Nurse... I am so pleased to now have access to this site for my future learning and development. Nurse and Medical Student 20 May 2016

I just completed the iron deficiency anemia course. It was brilliant. I enjoyed doing this course, and the convenience to do this at home in broken sessions was great, making it very achievable. Remote Area Nurse/Midwife 2 April 2016

I think these short on-line courses make it easy for nurses to access and reinforce their knowledge, whereas they may be apprehensive embarking on a large arduous program. Nurse 22 April 2016

This course can be used as a quick reference and refresher guide because of its easy to follow, precise setup and concise information. Midwife 6 October 2015 
Feedback on the education strategy and design shows that users relate to the contextual case studies, peer and expert videos and interactive elements.

Recommendations and areas for further development include:

- Targeting health professions' students in order to provide foundational knowledge;

- Increasing promotion and marketing to specific user groups;

- Creating a range of face-to-face resources to support the online courses, which can be used by hospital educators to provide a blended approach to transfusion education and training; and

- Expanding the range of courses available to provide a comprehensive education program that includes other blood components such as fresh frozen plasma and coagulation factor replacements.

\section{$4 \quad$ Future Direction}

There are a number of areas identified for development in the future. These include:

- Implementing a more comprehensive evaluation program that attempts to use qualitative measures to gauge effectiveness. Examples of such measures could include analysis of blood usage, audits of transfusion decision-making, informed consent and prescribing practices, and comparison of adverse event frequency as a result of human error before and after course completion. Some of the challenges associated with this will be availability of data, and separating out the impact of education from a range of other interventions (eg development of guidelines) in the blood sector;

- Expanding the number and type of courses available to provide additional topics;

- Developing supporting resources that can be used by hospital-based educators in a blended learning environment; and

- Leveraging the current investment to provide a service to countries outside of Australia, particularly in the Asia-Pacific region given the close relationship Australia has with these areas of the world. The challenges associated with this include the need to modify some aspects of the program to the local context, language barriers, availability of adequate internet and ICT infrastructure, and identification of funding sources.

\section{Conclusion}

The BloodSafe eLearning Australia program has provided learning and development to a large number of health professionals in Australia. Evaluation of user feedback demonstrates that these courses provide users with a consistent and reliable knowledge base and helps to identify opportunities to improve practice and patient outcomes. 


\section{Acknowledgments}

The authors thank Dr Amanda Thomson, Sue Ogley and Leonie Lower. They also acknowledge the support and work of Dr Alison Russell, Dr Ian Bone, Greg Opie the Digital Media Unit, Women's and Children's Hospital, North Adelaide, Australia, Brightcookie Pty Ltd, the National Blood Authority, the South Australian Department of Health and Ageing and the Australian Red Cross Blood Service.

\section{$7 \quad$ References}

[1] Old Testament Leviticus 17:11.

[2] E Rossi and T Simon. Principles of transfusion medicine $5^{\text {th }}$ ed. John Wiley and Sons Ltd, 2016. p1.

[3] H Tucker. "Blood lust: the early history of transfusion". Scientific American 2011. URL: https://blogs.scientificamerican.com/guest-blog/blood-lust-the-early-history-of-transfusion Accessed 3 March 2017.

[4] Pierce, Steven, Reid, Marion. Bloody Brilliant: A history of blood groups and blood groupers. AABB Press Bethesda 2016. p27.

[5] 10 facts on blood transfusion. World Health Organisation June 2016. URL: http://www.who.int/features/factfiles/blood transfusion Accessed 10 March 2017.

[6] Annual SHOT report 2015 summary. Serious Hazards of Transfusion Program Manchester UK. 2015. URL: http://www.shotuk.org/wp-content/uploads/SHOT-SummaryInfographic Final.pdf. Accessed 3 March 2017.

[7] Annual Report National Blood Authority: Objective 1. Secure the supply of blood and blood products. National Blood Authority Australia 2016. URL: http://www.blood.gov.au/pubs/1516report/part-2-annual-performance/objective-1-securesupply-blood-and-blood-products.html Accessed 5 March 2017.

[8] A Hoffmann, S Farmer and S Towler. "Strategies to preempt and reduce the use of blood products: an Australian perspective". Curr. Op. Anaesth. 25(1): 2011, pp66-73. https://doi.org/10.1097/ACO.0b013e32834eb726

[9] Australian haemovigilance report, data for 2013-14. National Blood Authority, Canberra Australia. 2016. URL: https://www.blood.gov.au/system/files/Australian-HaemovigilanceReport-2016.pdf Accessed 28 February 2017.

[10] Leahy, M. F., Hofmann, A., Towler, S., Trentino, K. M., Burrows, S. A., Swain, S. G., Hamdorf, J., Gallagher, T., Koay, A., Geelhoed, G. C. and Farmer, S. L. (2017), "Improved outcomes and reduced costs associated with a health-system-wide patient blood management program: a retrospective observational study in four major adult tertiary-care hospitals" Transfusion. URL: https://onlinelibrary.wiley.com/doi/10.1111/ trf.14006/full Accessed 15 March 2017. https://doi.org/10.1111/trf.14006

[11] National Blood Authority. Patient Blood Management Guidelines. National Blood Authority, Australia. 2012-2016. URL: https://www.blood.gov.au/pbm-guidelines. Accessed 16 February 2017.

[12] Australian and New Zealand Society of Blood Transfusion (ANZSBT). Administration of blood products $2^{\text {nd }}$ ed. 2011. URL: https://www.anzsbt.org.au/pages/anzsbtguidelines.html. Accessed 12 March 2017.

[13] Australian Commission on Safety and Quality in Health Care, National Safety and Quality Health Service Standards. September 2012. Sydney. ACSQHC, 2012, pp48-53. 
[14] Herrington, J, Oliver, R, “An instructional design framework for authentic learning environments" Educational Technology Research and Development 48(3), 2000, pp23-48. https://doi.org/10.1007/BF02319856

[15] Annual Report 2015/16. Australian Health Practitioner Regulation Agency (AHPRA) 2016. URL: http://www.ahpra.gov.au/annualreport/2016/downloads.html. Accessed 21 January 2017.

[16] NOUS Group. Business Model Report BloodSafe eLearning Australia 30 January 2015. Unpublished.

\section{Authors}

David Peterson is Manager at BloodSafe eLearning Australia, Centre for Education and Training, Women's and Children's Hospital, North Adelaide, SA 5006 Australia.

Tracey Clark is Quality Assurance Officer at BloodSafe eLearning Australia, Centre for Education and Training, Women's and Children's Hospital, North Adelaide, SA 5006 Australia.

Richard Sprod is Data Evaluation Lead at BloodSafe eLearning Australia, Centre for Education and Training, Women's and Children's Hospital, North Adelaide, SA 5006 Australia.

Trudi Verrall is Clinical Education Lead at BloodSafe eLearning Australia, Centre for Education and Training, Women's and Children's Hospital, North Adelaide, SA 5006 Australia.

Louise English is Clinical Education Project Officer at BloodSafe eLearning Australia, Centre for Education and Training, Women's and Children's Hospital, North Adelaide, SA 5006 Australia.

This article is a revised version of a paper presented at the International Conference on E-learning in the Workplace 2017 (ICELW 2017), held in June 2017, at Columbia University in New York, NY, USA. Article submitted 17 March 2017. Published as resubmitted by the authors 8 May 2017.

This program is funded by all Australian governments, through the National Blood Authority, Australia. In-kind support is provided by the South Australian Department of Health and the Women's and Children's Health Network, South Australia. 